\title{
COLD NEUTRON PROMPT GAMMA ACTIVATION ANALYSIS AT NIST: A PROGRESS REPORT
}

\author{
R. L. PAUL, * R. M. LINDSTROM,* D. H. VINCENT** \\ *Inorganic Analytical Research Division, National Institute of Standards and Technology, \\ Gaithersburg, MD 20899 (USA) \\ ${ }^{* *}$ Department of Nuclear Engineering, The University of Michigan, Ann Arbor, Michigan 48109 (USA)
}

(Received January 4, 1994)

\begin{abstract}
An instrument for prompt gamma-ray activation analysis is now in operation at the NIST Cold Neutron Research Facility (CNRF). The cold neutron beam is relatively free of contamination by fast neutrons and reactor gamma rays, and the neutron fluence rate is $1.5 \cdot 10^{8} \mathrm{~cm}^{-2} \cdot \mathrm{s}^{-1}$ (thermal equivalent). As a result of a compact target-detector geometry the sensitivity is better by a factor of as much as seven than that obtained with an existing thermal instrument, and hydrogen background is a factor of 50 lower. We have applied this insirument to multielement analysis of the Allende meteorite and other materials.
\end{abstract}

In recent years prompt gamma-ray activation analysis (PGAA) has taken its place alongside conventional neutron activation analysis as an important analytical method 1,2 . The technique is particularly useful in that it allows nondestructive determination of elements (e.g. $\mathrm{H}$, $B, C, N$ ) that cannot be measured by conventional activation analysis. Disadvantages of PGAA in the past have included relatively low sensitivities for many elements and the problem of shielding the detector from the fast neutrons and reactor gamma-rays that accompany the thermal neutrons normally used in the analysis. These disadvantages have been overcome to a large extent by the use of "cold" neutrons 3 .

An instrument for prompt gamma-ray activation analysis has been in operation at the Cold Neutron Research Facility (CNRF) at the National Institute of Standards and Technology Research Reactor since 1990. This instrument has higher sensitivities for most elements and lower environmental background than the University of Maryland-NIST thermal PGAA instrument (also at this reactor) and is therefore more suitable for the determination of elements at $\mu \mathrm{g}$ levels. The present work describes the cold neutron instrument and some of the more recent applications of the technique.

\section{Materials and Methods}

The Cold Neutron Research Facility ${ }^{4}$ and PGAA instrument ${ }^{5}$ have been described in detail elsewhere. Eight beam ports supply neutrons to fourteen different instruments (Figure 1). The cold neutrons which supply these instruments are produced in a $16-\mathrm{L} \mathrm{D}_{2} \mathrm{O}$ ice moderator at approximately $30 \mathrm{~K}$ near the reactor core. These neutrons are filtered through $127 \mathrm{~mm}$ Be and 178 $\mathrm{mm}$ single crystal $\mathrm{Bi}$ (both at $77 \mathrm{~K}$ ) and travel through the lower half of neutron guide $\mathrm{NG7}$ on their way to the PGAA station in the guide hall. (The upper half of the guide continues on to a $30-\mathrm{m}$ SANS instrument.) The neutron beam is virtually free of epithermal and fast neutrons as well as reactor gamma rays. The neutron flux at the sample position ( $41 \mathrm{~m}$ from the cold source) has been measured with $25 \mu \mathrm{m}$ Au foils to be $1.5 \times 10^{8} \mathrm{~cm}^{-2} \mathrm{~s}^{-1}$ (thermal equivalent, using $\sigma=\sigma \mathrm{th}=98.65$ b). 


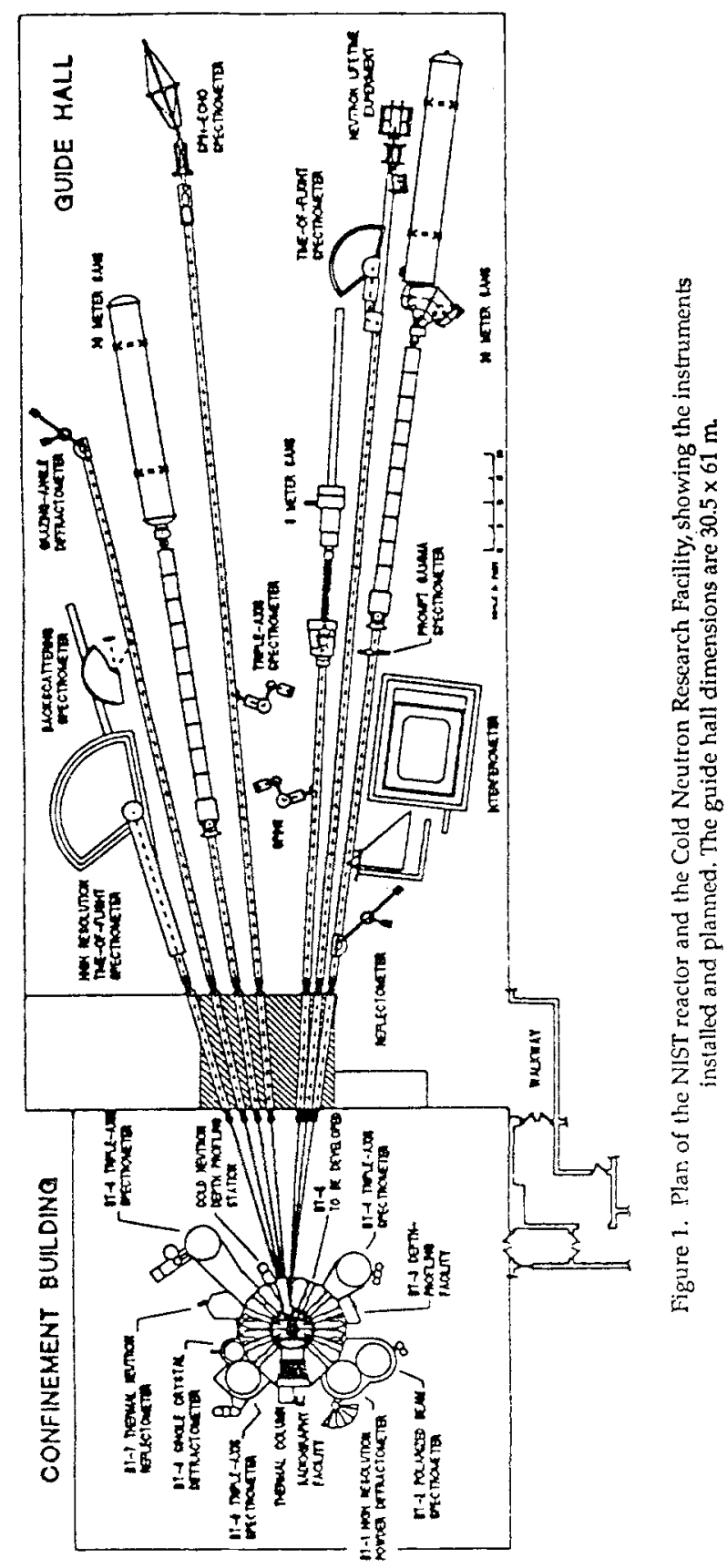



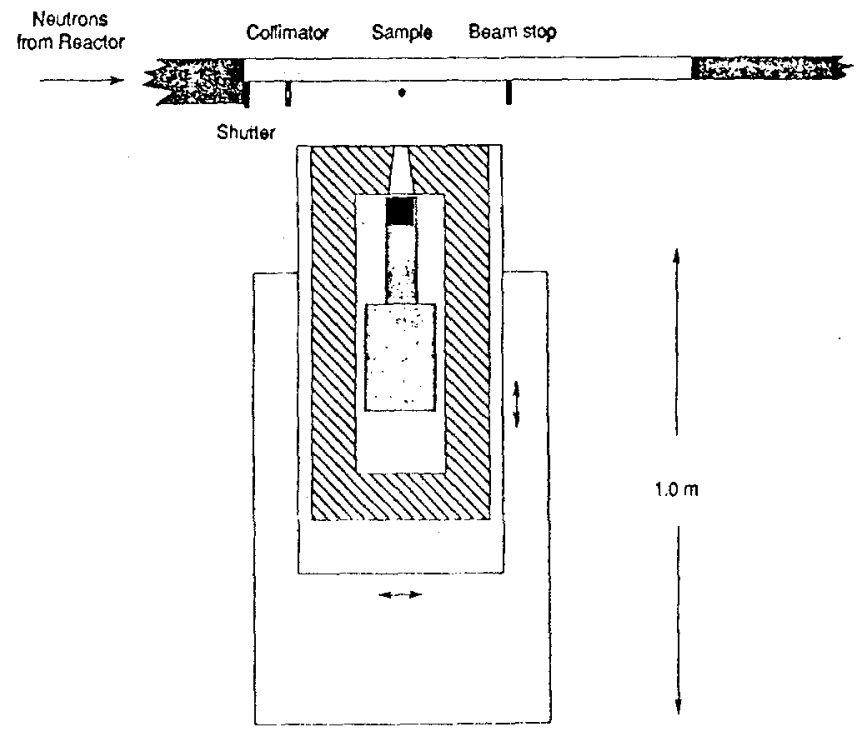

Figure 2. Scale drawing of the PGAA spectrometer. The detector and shield are shown in cross section from a top view and the guide is shown from the side, rotated about the sample position.

Figure 2 shows the experimental setup at the PGAA work station in the guide hall. The neutron beam emerges from the guide through a $0.25 \mathrm{~mm}$ thick window of magnesium alloy, and is collimated by a plate of fused $6 \mathrm{Li}_{2} \mathrm{CO}_{3}$ with a $2.1 \mathrm{~cm}$ aperture before striking the sample. Samples for irradiation are usually sealed inside small bags of FEP Teflon and suspended by Teflon string between the prongs of an aluminum fork. A beam stop of $6 \mathrm{Li}$ glass 6 is mounted behind the sample position to absorb residual neutrons. The flow of neutrons to the target is controlled by means of a shutter of 6 Li glass mounted at the end of the neutron guide.

Prompt gamma-rays emitted from the sample are detected using a Ge gamma-ray detector with 27 percent efficiency (relative to $\mathrm{Nal}$ ) and $1.7 \mathrm{keV}$ resolution, positioned with its axis perpendicular to the neutron guide. The detector is shielded from environmental gamma rays with at least $100 \mathrm{~mm}$ of lead in all directions. The lead in turn is shielded from stray neutrons with sheets of boral to prevent production of $7-\mathrm{MeV} \mathrm{Pb}$ capture gamma-rays. Gamma-rays from the sample enter the detector through a $2 \mathrm{~cm}$ aperture of a copper collimator. The entrance to the collimator is covered by a 6 Li glass window to prevent stray neutrons from entering the detector. The shieided detector is mounted on a movable table, which rolls on a track perpendicular to the neutron beam to adjust the counting distance.

Gamma-ray spectra are taken using a 16384-channel fixed conversion time analog-digital converter (Canberra Nuclear Data ND582) coupled to a multichannel pulse height analyzer (ND556 AIM). The AIM is connected through the the building-wide Ethernet to a VAXstation 3100 where data acquisition is performed using Nuclear Data acquisition and display software. Data reduction and spectral manipulation are accomplished using Nuclear Data spectroscopy applications software, which includes a peak search, a sum program (written at NIST) useful for integrating background level peaks, and the recently acquired Hypermet peak search program. 


\section{Sensltivlty and Background}

As stated earlier, the principle advantages of the cold-neutron PGAA instrument over the UMd-NIST thermal instrument are higher sensitivity and lower background for most elements. Largely because of compact target-to-detector geometry (targets may be counted as close as 19 $\mathrm{cm}$ from the face of the detector) the sensitivity (counting rate per gram of analyte) is better by a factor of as much as 7 than that obtained by the thermal PGAA instrument.

Unlike the neutron beam of the UMd-NIST thermal instrument, which contains about $2 \%$ epithermal neutrons, the cold neutron beam is essentially free of epithermal and fast neutrons. Hence the cold neutron instrument has no need for the massive quantities of paraffin and boron carbide shielding used in thermal neutron PGAA, and background radiation levels (particularly due to neutron capture by environmental $H$ and $B$ ) are lower. Nevertheless some background radiation is observed. Prior to reconfiguring the apparatus (see below), we reported significant levels of $\mathrm{Si}$ and $\mathrm{H}$ in the background spectrum ${ }^{5}$. Most of this background radiation is emitted by the upper portion of neutron guide NG7 which continues past the PGAA work station to the velocity selector of a 30-m SANS instrument. To avoid a high background from boron capture gamma rays, the $1-\mathrm{m}$ section of the guide facing the PGAA work station is composed of boronfree glass instead of the borosilicate glass normally used. Neutron background is reduced by a coating of ${ }^{6} \mathrm{Li}$-graphite paint applied to the outside of the guide. Gamma rays from neutron capture by $S i$ in the glass of the guide account for the observed silicon background. The hydrogen background may be due in large part to hydrogen present in the paint coating the guide. High energy capture peaks from the nickel lining of the guide are also observed in the background spectrum. With the shutter open, capture gamma rays from nitrogen and even argon in the air may be detected.

Recent attempts to reduce these sources of background have met with some success. Neutron capture from nitrogen and argon in the air may be reduced by flooding the volume between the neutron collimator and the beam stop with $\mathrm{He}$ in a Teflon tent. The construction of a $4 \mathrm{~cm}$ thick wall of lead bricks (with a $2 \mathrm{~cm}$ aperture in the target position), supported by an aluminum rack, between the detector and the neutron guide resulted in a six-fold reduction in the silicon background while reducing the hydrogen background to $20 \mu \mathrm{g}$ or less (at least 50 times lower than the $\mathrm{H}$ background for the thermal instrument). However, this construction also resulted in an increase in background due to neutron capture by aluminum and lead, as well as reduced counting efficiency since the detector-to-target distance was increased to $24 \mathrm{~cm}$. The design and installation of permanent shielding around the neutron guide may eliminate some of these problems.

\section{Applications}

The wholly instrumental, nondestructive, multielement nature of PGAA makes it applicable to the solution of a number of problems in chemical analysis. Although a fair number of elements may be determined by PGAA, the technique is particularly important for the measurement of elements which absorb neutrons but do not form radioactive products. These elements include boron, carbon, nitrogen, and especially hydrogen, which cannot be readily determined in trace amounts by any other method 7 . Because the technique is nondestructive, analyses can often be performed rapidly with little or no sample preparation involved. Hence the technique is particularly well suited for rapid qualitative and quantitative analysis of materials in order to establish the presence or absence of an element or to determine elemental molar ratios to establish the chemical formula of a compound. 
To illustrate the multielement capability of the cold neutron PGAA instrument we analyzed a smail sample of the Allende meteorite. The sample was prepared by mixing $0.82 \mathrm{~g}$ of Allende powder with graphite, then pressing the mixture into a cylindrical disk. The disk was then irradiated in the neutron beam for approximately two hours. A total of fourteen elements were identified in the gamma-ray spectrum; standards for these elements were also prepared and analyzed. Considerable effort was made to keep standard geometries consistent with that of the Allende pellet. For some elements numerous standards were tried before a suitable one was found. The final standards used in the analysis fall into three categories: 1) small metal pieces, 2) powdered samples pressed into cylindrical disks, and 3) powdered samples mixed with graphite, then pressed into cylindrical disks. Because the Allende sample was mixed with graphite, a 1.76 $\mathrm{g}$ graphite disk was run as a blank. This blank was found to contain considerable $\mathrm{Al}$ and $\mathrm{H}$, giving backgrounds of $1.10 \mathrm{c} / \mathrm{s} \mathrm{Al}$ and $0.13 \mathrm{c} / \mathrm{s} \mathrm{H}$ above the normal backgrounds for these elements. Table 1 lists peak energy, count rate, sensitivity, background and standard used for each element determined in Allende.

Elemental concentrations were calculated as either \% by weight of sample or as parts per million $(\mathrm{ppm})$ of sample weight. These values are in fair agreement with values given by Jarosewich ${ }^{8}$. Hydrogen concentrations from $\mathrm{Scoon}^{10}$ and Willis ${ }^{11}$ were determined as $\mathrm{H}_{2} \mathrm{O}$ using

Table 1 - Counting data for elements found in Allende

\begin{tabular}{|c|c|c|c|c|c|}
\hline Element & $\begin{array}{l}\text { Peak } \\
\text { Energy } \\
(\mathrm{keV})\end{array}$ & $\begin{array}{l}\text { Count } \\
\text { Rate } \\
(\mathrm{c} / \mathrm{s})\end{array}$ & Standard & $\begin{array}{c}\text { Sensitivity } \\
(\mathrm{c} / \mathrm{s} / \mathrm{g})\end{array}$ & $\begin{array}{l}\text { Background } \\
\text { (c/s) }\end{array}$ \\
\hline $\mathrm{Si}$ & 3538 & $4.77 \pm 0.03$ & $\mathrm{Si}$ & 28.0 & 1.24 \\
\hline $\mathrm{Fe}$ & 352 & $35.3 \pm 0.1$ & $\mathrm{Fe}$ & 204 & ----- \\
\hline $\mathrm{Mg}$ & 585 & $3.96 \pm 0.05$ & $\mathrm{Mg}$ & 35.7 & $\cdots$ \\
\hline A & $1778 D^{*}$ & $2.89+0.04$ & Al & 109 & 1.38 \\
\hline $\mathrm{Ca}$ & 1942 & $1.28 \pm 0.03$ & $\mathrm{CaCO}_{3}$ & 96.6 & $\ldots . .$. \\
\hline $\mathrm{Ni}$ & 465 & $4.86 \pm 0.05$ & $\mathrm{Ni}+\mathrm{Graphite}$ & 376 & -...- \\
\hline S & 841 & $3.77 \pm 0.03$ & $\mathrm{Na}_{2} \mathrm{SO}_{4}$ & 221 & $\ldots$ \\
\hline $\mathrm{Cr}$ & 835 & $1.62 \pm 0.03$ & $\mathrm{Cr}$ & 462 & ---- \\
\hline $\mathrm{Mn}$ & 105 & $1.95 \pm 0.06$ & $\mathrm{Mn}$ & 1280 & $\cdots$ \\
\hline $\mathrm{Na}$ & 472 & $1.63 \pm 0.04$ & $\mathrm{Na}_{2} \mathrm{SO}_{4}$ & 660 & $\cdots-$ \\
\hline $\mathrm{Ti}$ & 1381 & $1.10 \pm 0.04$ & $\mathrm{Ti}$ & 1614 & ---- \\
\hline $\mathrm{Cl}$ & 1165 & $1.09 \pm 0.04$ & $\mathrm{NaCl}$ & 4640 & ---- \\
\hline$H$ & 2223 & $0.67 \pm 0.03$ & $\begin{array}{l}\text { THAM\# } \\
\text { in Graphite }\end{array}$ & 3970 & 0.17 \\
\hline$K$ & 770 & $0.16_{ \pm} 0.03$ & $\mathrm{~K} \mathrm{O}_{3}$ & 520 & ----- \\
\hline
\end{tabular}

* $D$ indicates a decay gamma ray rather than a prompt.

\#Trishydroxymethylaminomethane 
the Penfield water determination method. These results are in fair agreement with our total hydrogen concentration.

In order to illustrate the ability of PGAA to rapidly comfirm or disprove the chemical formula of a compound, we offer the following two examples:

We were given a sample of a substituted fullerene, labelled $\mathrm{K}_{6} \mathrm{C}_{60}$, intended to be used in neutron scattering measurements 7 . We were asked to measure hydrogen, potassium, and carbon and to determine the $\mathrm{C} / \mathrm{H}$ and $\mathrm{K} / \mathrm{H}$ molar ratios. After repeated efforts to locate a potassium peak in the gamma-ray spectrum, we concluded that potassium was not present in the sample. We did however determine that the sample contained $106 \pm 5 \mathrm{mg} \mathrm{Rb}$ and $150 \pm 18 \mathrm{mg} \mathrm{C}$. After calculating the $\mathrm{C} / \mathrm{Rb}$ molar ratio to be 10.0 , we concluded that the sample was $\mathrm{Rb}_{6} \mathrm{C}_{60}$, and not $\mathrm{K}_{6} \mathrm{C}_{60}$ as was originally believed.

As a second example of this type of analysis, we were asked to ascertain the identity of a transition metal complex. In support of work being done on the accurate assay of noble metals, we were given a complex of rhodium and asked to measure rhodium, hydrogen, and chlorine. The complex was labelled $\left(\mathrm{NH}_{4}\right)_{3}\left[\mathrm{RhCl}_{6}\right]$, but could have been any one of a number of related rhodium complexes (e.g. $\left(\mathrm{NH}_{4}\right)_{2}\left[\mathrm{RhCl}_{5}\left(\mathrm{H}_{2} \mathrm{O}\right)\right.$ ], $\mathrm{NH}_{4}\left[\mathrm{RhCl}_{4}\left(\mathrm{H}_{2} \mathrm{O}\right)_{2}\right]$, or $\mathrm{RhCl}_{3}\left(\mathrm{H}_{2} \mathrm{O}_{3}\right)^{12}$ ). The complex was irradiated in the neutron beam for 50 minutes and was found to contain $0.20 \pm 0.02$ $\mathrm{mg}$ of $\mathrm{H}, 3.80 \pm 0.02 \mathrm{mg}$ of $\mathrm{Cl}$ and $2.8 \pm 0.1 \mathrm{mg}$ of Rh. We then calculated the molar ratios to be $\mathrm{H} / \mathrm{Cl}=1.8, \mathrm{Cl} / \mathrm{Rh}=4.0, \mathrm{H} / \mathrm{Rh}=7.3$. These ratios are close but not equal to the expected molar ratios for the complex $\mathrm{NH}_{4}\left[\mathrm{Rb}\left(\mathrm{H}_{2} \mathrm{O}\right)_{2} \mathrm{Cl} 4\right](\mathrm{H} / \mathrm{Cl}=2, \mathrm{Cl} / \mathrm{Rh}=4$, and $\mathrm{H} / \mathrm{Rh}=8)$. We concluded that the sample was probably a mixture of two or more rhodium complexes.

\section{Conclusions and Future Plans}

The design and installation of additionai permanent shielding around the neutron guide and the addition of a Compton suppressor to the system in the near future should greatly reduce background. Long range plans to improve the counting system include the installation of a new cold source, which will increase the neutron fluence rate by a factor of up to five, the addition of an automatic sample changer, and neutron optics to focus cold neutrons onto a small area. The latter may result in a gain of an order of magnitude in fluence rate 13,14 .

We wish to thank W.A. Bowman and J.K. Langland for design and construction, and J.R.D. Copley and R.R. Greenberg for suppiying analytical samples. The identification of certain commercial equipment, instruments, or materials does not imply recommendation or endorsement by the National Institute of Standards and Technology. These identifications are made only in order to specify the experimental procedures in adequate detail.

\section{References}

1. M. P. FAILEY, D. L. ANDERSON, W. H. ZOLLER, G. E. GORDON, R. M. LINDSIROM, Anal. Chem., 51 (1979) 2209.

2. A. G. HANNA R. M. BRUGGER, M. D. GLASCOCK, Nucl. Inst. Methods., 188 (1981) 619.

3. R. M. LINDSTROM, R. ZEISLER, M. ROSSBACH, J. Radioanal. Nucl. Chum., 112 (1987) 321. 
4. H. J. PRASK, J. M. ROWE, J. J. RUSH, I. G. SCHRÖDER, submitted to J. Res. NIST.

5. R. M. LINDSTROM, R. ZEISLER, D. H. VINCENT, R. R. GREENBERG, C. A. STONE, E. A. MACKEY, D. L. ANDERSON, D. D. CLARK, J. Radioanal. Nucl. Chem., (in press).

6. C. A. STONE, R. ZEISLER, D. H. BLACKBUM, D. A. KAUFFMANN, D. C. CRANMER, in: NIST Techn. Note 1285, U.S. Govt. Print. Off., Washington, D. C., 1990, p. 116.

7. R. M. LINDSTROM, R. L. PAUL, D. H. VINCENT, R. R. GREENBERG, this Proceedings.

8. E. JAROSEWICH,, R. S. CLARKE Jr., J. N. BARROWS, Neutron Activation Analyses of Seven Elements in the Allende Meteorite Reference Sample, in: The Allende Meteorite Reference Sample, E. JAROSEWICH, R. S. CLARKE Jr., J. N. Barrows (Eds), Smithsonian Contrib, Earth Sci., 27 (1987) 1.

9. K. S. HEIR, A. O. BRUMFELT, E. STEINNES, B. SUNDVOLL, Neutron Activation Analyses of Seven Elements in the Allende Meteorite Reference Sample, in: The Allende Meteorite Reference Sample, E. JAROSEWICH, R. S. CLARKE Jr., J. N. Barrows (Eds), Smithsonian Contrib., Earth Sci., 27 (1987) 24.

10. J. H. SCOON, Bulk Chemical Analysis of the Allende Meteorite Reference Sample, in: The Allende Meteorite Reference Sample, E. JAROSEWICH, R. S. CLARKE, Jr., J. N. Barrows (Eds), Smithsonian Contrib, Earth Sci., 27 (1987) 39.

11. J. P. WILLIS, X-ray Fluorescence Spectrometric Analysis of the Allende Meteorite Reference Sample, in: The Allende Meteorite Reference Sample, E. JAROSEWICH, R. S. CLARKE, Jr., J. N. Barrows (Eds), Smithsonian Contrib., Earth Sci., 27 (1987) 46.

12. F. A. COTTON, G. WILKINSON, Advanced Inorganic Chemistry, John Wiley and Sons, New York, 1980, p. 944.

13. M. ROSSBACH, O. SCHÄRPF, W. KAISER, W. GRAF, A. SCHIRMER, W. FABER, J. DUPPICH, R. ZEISLER, Nucl. Instrum. Methods, B35 (1988) 181.

14. D. F. R. MILDNER, Nucl. Instrum. Methods, A299 (1990) 416. 